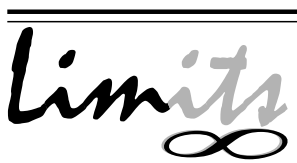

J. Math. and Its Appl.

ISSN : 1829-605X

Vol. 4, No. 1, May 2007, 17-25

\title{
Konstruksi Matriks NonNegatif Simetri dengan Spektrum Bilangan Real
}

\author{
Bambang Sugandi ${ }^{1}$ dan Erna Apriliani ${ }^{2}$ \\ ${ }^{1}$ Jurusan Matematika, FMIPA Unibraw, Malang \\ bamsugan@brawijaya.ac.id \\ ${ }^{2}$ Jurusan Matematika, FMIPA ITS, Surabaya \\ april@matematika.its.ac.id
}

\begin{abstract}
Abstrak
Diberikan suatu himpunan bilangan real $\Lambda=\left\{\lambda_{1}, \lambda_{2}, \cdots, \lambda_{n}\right\}$. Jika terdapat matriks nonnegatif simetri $A_{n \times n}$ dengan spektrum $\Lambda$, maka spektrum dapat direalisasikan oleh matriks $A$. Pada makalah ini ditunjukkan bahwa eksistensi matriks nonnegatif simetri $A$ ditentukan dengan menggunakan kriteria realisasi. Selanjutnya, matriks nonnegatif simetri dapat dikonstruksi dengan menggunakan jumlah langsung. Disini diberikan sebuah contoh konstruksi matriks nonnegatif simetri.
\end{abstract}

Kata Kunci: konstruksi, realisasi, spektrum, matriks nonnegatif simetri

\section{Pendahuluan}

Konstruksi matriks nonnegatif simetri dengan spektrum bilangan real adalah tahapan pembentukan matriks nonnegatif simetri, jika diberikan spektrumnya berupa bilangan real. Konstruksi matriks dapat dilakukan jika kriteria realisasi matriks dipenuhi.

Dalam R.Soto [5], dikemukakan tentang realisasi matriks nonnegatif dengan spektrum bilangan real, yang isinya menyangkut syarat cukup untuk keberadaan 
matriks nonnegatif dengan spektrum bilangan real. Sedangkan dalam R.Soto [6], dikemukakan tentang realisasi matriks nonnegatif simetri, yang menjelaskan mengenai berlakunya syarat cukup [5] untuk matriks nonnegatif simetri dan konstruksinya.

Dalam tulisan ini akan dibahas mengenai kontruksi matriks nonnegatif simetri dengan spektrum bilangan real. Diberikan beberapa lemma dari M.Fiedler [2] yang sangat mendukung dalam penyelesaian konstruksi. Diberikan juga contoh konstruksi matriks nonnegatif dari spektrum bilangan real.

\section{Beberapa Definisi dan Lemma}

Pada bab ini diberikan beberapa definisi dan lemma yang berkaitan dengan konstruksi suatu matriks, antara lain spektrum matriks, realisasi matriks, jumlah langsung serta beberapa lemma

\section{Definisi 2.1 Spektrum Matriks}

Misalkan $\lambda_{1}, \lambda_{2}, \cdots, \lambda_{n}$ adalah nilai-nilai eigen matriks $A$ dengan orde $n$. Maka spektrum dari $A$ yang dinyatakan dengan $\Lambda(A)$ adalah himpunan semua nilainilai eigen dari $A$, atau $\Lambda(A)=\left\{\lambda_{1}, \lambda_{2}, \cdots, \lambda_{n}\right\}$. Jika $A$ merupakan matriks simetri dengan unsur real, maka nilai-nilai eigennya bilangan real, sehingga $\Lambda(A)$ merupakan sebuah himpunan bilangan real [1, 3].

\section{Definisi 2.2 Realisasi Matriks}

Misalkan $\Lambda=\left\{\lambda_{1}, \lambda_{2}, \cdots, \lambda_{n}\right\}$ suatu himpunan bilangan real dengan $\lambda_{1} \geq \lambda_{2} \geq$ $\cdots \geq \lambda_{p} \geq \lambda_{p+1} \geq \cdots \geq \lambda_{n}$, akan ditentukan matriks nonnegatif $A_{n \times n}$ sedemikian sehingga $\Lambda$ merupakan spektrum dari $A$. Jika terdapat matriks nonnegatif $A_{n \times n}$ dengan spektrum $\Lambda$, maka dikatakan bahwa $\Lambda$ direalisasikan oleh A[6].

\section{Definisi 2.3 Jumlah Langsung Matriks}

Suatu matriks $A_{n \times n}$ blok diagonal adalah suatu partisi matriks $A=\left(A_{i j}\right)$, dengan:

i. setiap $A_{i i}$ merupakan matriks bujur sangkar

ii. Jika $i \neq j, A_{i j}$ merupakan matriks yang semua elemen-elemennya 0.

Jika $A=\left(A_{i j}\right)$ adalah blok diagonal, maka $A$ merupakan jumlah langsung dari $A_{11}, A_{22}, \cdots, A_{t t}$ atau $A=A_{11} \oplus A_{22} \oplus \cdots \oplus A_{t t} \cdot[\eta]$

Di bawah ini akan diberikan beberapa lemma penting yang sangat mendukung untuk pembuktian teorema maupun konstruksi matriks nonnegatif simetri. 
Lemma 2.4 [2]

Misalkan A suatu matriks simetri $n \times n$ dengan nilai eigen $\lambda_{1}, \lambda_{2}, \cdots, \lambda_{n} . M i$ salkan $\bar{v},\|\bar{v}\|=1$, merupakan vektor eigen satuan dari $A$ yang berkaitan dengan $\lambda_{1}$. Misalkan $B$ suatu matriks simetri $m \times m$ dengan nilai eigen $\beta_{1}, \beta_{2}, \cdots, \beta_{m}$. Misalkan $\bar{u},\|\bar{u}\|=1$ merupakan vektor eigen satuan dari $B$ yang berkaitan dengan $\beta_{1}$, maka untuk sembarang $\rho$, matriks

$$
C=\left(\begin{array}{cc}
A & \rho \bar{u} \bar{v}^{T} \\
\rho \bar{u} \bar{v}^{T} & B
\end{array}\right)
$$

mempunyai nilai eigen $\lambda_{2}, \cdots, \lambda_{n}, \beta_{2}, \cdots, \beta_{m}, \gamma_{1}, \gamma_{2}$ dimana $\gamma_{1}$ dan $\gamma_{2}$ merupakan nilai eigen dari matriks

$$
\bar{C}=\left(\begin{array}{cc}
\alpha_{1} & \rho \\
\rho & \beta_{1}
\end{array}\right)
$$

Lemma $2.5[2]$

Jika $\left\{\alpha_{1}, \alpha_{2}, \cdots, \alpha_{n}\right\} \in S_{n},\left\{\beta_{1}, \beta_{2}, \cdots, \beta_{m}\right\} \in S_{m}$ dan $\varepsilon \geq \max \left\{0, \beta_{1}-\alpha_{1}\right\}$ maka $\left\{\alpha_{1}+\varepsilon, \beta_{1}-\varepsilon, \alpha_{2}, \cdots, \alpha_{n}, \beta_{2}, \cdots, \beta_{m}\right\} \in S_{n+m}$.

Lemma 2.6 [2]

Jika $\Lambda=\left\{\lambda_{0}, \lambda_{1}, \cdots, \lambda_{n-1}\right\} \in S_{n}$, dan $\varepsilon>0$, maka $\left\{\alpha_{0}+\varepsilon, \alpha_{1}, \cdots, \alpha_{n-1}\right\} \in \bar{S}_{n}$.

\section{Kriteria Realisasi Matriks Nonnegatif Simetri}

Berikut ini akan ditunjukkan bahwa kriteria realisasi pada Teorema 3.1 merupakan syarat cukup untuk keberadaan matriks nonnegatif simetri dengan spektrum $\Lambda$.

Teorema $3.1[6]$

Misalkan $\Lambda=\left\{\lambda_{1}, \lambda_{2}, \cdots, \lambda_{n}\right\}$ merupakan himpunan bilangan real sedemikan sehingga $\lambda_{1} \geq \lambda_{1} \geq \cdots \lambda_{p} \geq 0 \geq \lambda_{p+1} \geq \cdots \geq \lambda_{n}$. Jika $\Lambda$ memenuhi kriteria realisasi yang diberikan dalam [5], yaitu $\lambda_{1} \geq-\lambda_{n}-\sum_{S_{k}<0} S_{k}$, dengan $S_{k}=\lambda_{k}+\lambda_{n-k+1}, k=2,3, \cdots,\left[\frac{n}{2}\right]$ dan $S_{\frac{n+1}{2}}=\min \left\{\lambda_{\frac{n+1}{2}}, 0\right\}$ untuk $n$ ganjil, maka $\Lambda$ direalisasikan oleh matriks nonnegatif simetri $A$ berorde $n \times n$.

\section{Bukti:}

Misalkan $\Lambda$ memenuhi kriteria realisasi, yaitu $\lambda_{1} \geq-\lambda_{n}-\sum_{S_{k}<0} S_{k}$ dengan $S_{k}=$ $\lambda_{k}+\lambda_{n-k+1}, k=2,3, \cdots,\left[\frac{n}{2}\right]$ dan $S_{\frac{n+1}{2}}=\min \left\{\lambda_{\frac{n+1}{2}}, 0\right\}$ untuk $n$ ganjil. Cukup dibuktikan untuk $\lambda_{1}=-\lambda_{n}-\sum_{S_{k}<0} S_{k}$, karena, jika $\lambda_{1}=-\lambda_{n}-\sum_{S_{k}<0} S_{k}$ dengan $\mu_{1}=-\lambda_{n}-\sum_{S_{k}<0} S_{k}$ maka dapat diambil $\bar{\Lambda}=\left\{\mu_{1}, \lambda_{2}, \cdots, \lambda_{n}\right\}$. Jadi, 
jika $\bar{\Lambda} \in S_{n}$ maka dengan menggunakan Lemma 2.6, $\varepsilon=\lambda_{1}-\mu_{1}>0$ menunjukkan bahwa $\Lambda \in \widehat{S}_{n}$.

Misalkan $\Lambda_{k}=\left\{\lambda_{k}, \lambda_{n-k+1}\right\} ; k=1,2, \cdots,\left[\frac{n}{2}\right]$ dan $\Lambda_{\frac{n+1}{2}}=\left\{\lambda_{\frac{n+1}{2}}\right\}$ untuk $n$ ganjil. Dengan $\left[\frac{n}{2}\right]$ adalah bilangan bulat terbesar yang lebih kecil atau sama dengan $\frac{n}{2}$.

Selanjutnya, bentuk partisi berikut, $\Lambda=\bigcup_{k=1}^{[n / 2]} \Lambda_{k}$ untuk $n$ genap, dan $\Lambda=$ $\bigcup_{k=1}^{[n / 2]} \Lambda_{k} \cup \Lambda_{\frac{n+1}{2}}$ untuk $n$ ganjil. Maka ada subset $\Lambda_{k}$ yang dapat direalisasikan oleh matriks nonnegatif simetri

$$
B_{k}=\frac{1}{2}\left(\begin{array}{cc}
\lambda_{k}+\lambda_{n-k+1} & \lambda_{k}-\lambda_{n-k+1} \\
\lambda_{k}-\lambda_{n-k+1} & \lambda_{k}+\lambda_{n-k+1}
\end{array}\right)
$$

Sehingga subset-subset $\Lambda_{k}$ di atas dapat dibagi dalam tiga kelompok yaitu:

a. Subset-subset $\Lambda_{k}$ yang dapat direalisasikan oleh matriks nonnegatif simetri $B_{k}$, atau $S_{k} \geq 0$.

b. Subset $\Lambda_{1}=\left\{\lambda_{1}, \lambda_{n}\right\}$ yang merupakan subset yang dapat direalisasikan oleh $B_{1}$.

c. Subset-subset $\Lambda_{k}$ yang tidak dapat direalisasikan oleh matriks nonnegatif simetri $B_{k}$, atau $S_{k}<0$

Masing-masing kelompok dapat dijelaskan sebagai berikut:

a. Susun subset-subset $\Lambda_{k}$ dengan $S_{k} \geq 0$, yang dinyatakan dengan $\Lambda_{t+1}, \cdots, \Lambda_{\left[\frac{n}{2}\right]}$ adalah subset-subset yang dapat direalisasikan. Selanjutnya, jika terdapat suatu subset $\Lambda_{k}$ yang dapat direalisasikan oleh matriks $B_{k}$ maka jumlah langsungnya berlaku:

i. untuk $n$ genap, $B=\bigoplus_{k=t+1}^{\left[\frac{n}{2}\right]} B_{k}$ adalah matriks nonnegatif simetri yang merealisasi $\Lambda=\bigcup_{k=t+1}^{\left[\frac{n}{2}\right]} \Lambda_{k}$, atau

ii. untuk $n$ ganjil $B=\bigoplus_{k=t+1}^{\left[\frac{n}{2}\right]} B_{k} \bigoplus B_{\frac{n+1}{2}}$ dengan $B_{\frac{n+1}{2}}=\left(\lambda_{\frac{n+1}{2}}\right)$, jika $\lambda_{\frac{n+1}{2}} \geq 0$ adalah matriks nonnegatif simetri yang merealisasi $\Lambda=$ $\bigcup_{k=t+1}^{\left[\frac{n}{2}\right]} \Lambda_{k} \cup \Lambda_{\frac{n+1}{2}}$.

b. Subset $\Lambda_{1}=\left\{\lambda_{1}, \lambda_{n}\right\}$ adalah subset yang dapat direalisasikan oleh $B_{1}$,

$$
B_{1}=\frac{1}{2}\left(\begin{array}{cc}
\lambda_{1}+\lambda_{n} & \lambda_{1}-\lambda_{n} \\
\lambda_{1}-\lambda_{n} & \lambda_{1}+\lambda_{n}
\end{array}\right)
$$


c. Susun subset-subset $\Lambda_{k}$ dengan $S_{k}<0$, yang dinyatakan dengan $\Lambda_{2}, \Lambda_{3}, \cdots, \Lambda_{t}, \quad t \leq\left[\frac{n}{2}\right]$ adalah subset-subset yang tak dapat direalisasikan. Jika terdapat suatu subset $\Lambda_{k}$, untuk $k=2,3, \cdots, t$ yang merupakan himpunan yang tak dapat direalisasikan; maka $\Lambda_{k}$ digabungkan dengan himpunan yang dapat direalisasikan $\Lambda_{1}=\left\{\lambda_{1}, \lambda_{n}\right\}$ dan susun kembali $2 t$ anggota dalam $\bigcup_{k=1}^{t} \Lambda_{k}$ sebagai berikut $\lambda_{1} \geq \lambda_{2} \geq \cdots \geq \lambda_{t} \geq \lambda_{t+1} \geq \cdots \geq \lambda_{2 t-1} \geq \lambda_{2 t}$. Kemudian untuk setiap satu dari himpunan $\lambda_{k}, k=1,2, \cdots, t$ didefinisikan himpunan yang bersesuaian $\Gamma_{k}=\left\{-\lambda_{2 t-k+1}, \lambda_{2 t-k+1}\right\}$ yang dapat direalisasikan oleh matriks nonnegatif simetri,

$$
A_{k}=\left(\begin{array}{cc}
0 & -\lambda_{2 t-k+1} \\
-\lambda_{2 t-k+1} & 0
\end{array}\right)
$$

dengan $\Gamma_{\frac{2 t+1}{2}}=\{0\}$ jika $\lambda_{\underline{2 T+1}}<0$ untuk $n$ ganjil, yang dapat direalisasikan oleh matriks nonnegatif simetri $A_{\frac{2 t+1}{2}}=(0)$.

Selanjutnya dilakukan langkah-langkah sebagai berikut:

Pertama, gabungkan himpunan-himpunan $\Gamma_{1}=\left\{-\lambda_{2 t}, \lambda_{2 t}\right\} \in S_{2}$ dan $\Gamma_{2}=$ $\left\{-\lambda_{2 t-1}, \lambda_{2 t-1}\right\} \in S_{2}$ untuk mendapatkan himpunan baru $\Delta_{2} \in S_{4}$, menurut Lemma 2.5 dengan mengambil $\varepsilon=-S_{2}=-\left(\lambda_{2}+\lambda_{2 t-1}\right)>0$, maka diperoleh

$$
\begin{gathered}
-\lambda_{2 t}+\varepsilon_{2}=-\lambda_{2 t}-S_{2}=-\lambda_{2}-\left(\lambda_{2}+\lambda_{2 t-1}\right) \\
-\lambda_{2 t-1}-\varepsilon_{2}=-\lambda_{2 t-1}+S_{2}=-\lambda_{2 t-1}+\left(\lambda_{2}+\lambda_{2 t-1}\right)=\lambda_{2}
\end{gathered}
$$

dan

$$
\Delta_{2}=\left\{-\lambda_{2 t}-S_{2}, \lambda_{2}, \lambda_{2 t-1}, \lambda_{2 t}\right\} \in S_{4}
$$

Selanjutnya, gabungkan $\Delta_{2}$ dengan $\Gamma_{3}=\left\{-\lambda_{2 t-2}, \lambda_{2 t-2}\right\}$. Ambil $\varepsilon_{3}=$ $-S_{3}=-\left(\lambda_{3}+\lambda_{2 t-2}\right)>0$, sehingga diperoleh $-\lambda_{2 t}-S_{3}+\varepsilon_{3}=-\lambda_{2 t}-$ $S_{2}-S_{3}$ maka $-\lambda_{2 t-2}-\varepsilon_{3}=-\lambda_{2 t-2}+S_{3}=-\lambda_{2 t-2}+\left(\lambda_{3}+\lambda_{2 t-2}\right)=$ $\lambda_{3}$ dan menurut Lemma 2.5 didapat $\Delta_{3}=\left\{-\lambda_{2 t}-S_{2}-S_{3}, \lambda_{3}, *, \cdots, *\right\} \in$ $S_{6}$. Dalam langkah ke- $j$ dari prosedur $(j \geq 2)$, gabungkan himpunanhimpunan $\Delta_{j}=\left\{-\lambda_{2 t}-S_{2}-S_{3}, \cdots, S_{j}, \lambda_{j}, *, \cdots, *\right\}$ dan $\Gamma_{j+1}=\left\{\lambda_{2 t-j}, \lambda_{2 t-j}\right\}$ dengan mengambil $\varepsilon_{j+1}=-S_{j+1}=-\left(\lambda_{j+1}+\lambda_{2 t-j}\right)$ maka diperoleh $-\lambda_{2 t}-$ $\sum_{k=2}^{j} S_{k}+\varepsilon_{j+1}=-\lambda_{2 t}-\sum_{k=2}^{j} S_{k},-\lambda_{2 t-j}-\varepsilon_{j+1}=-\lambda_{j+1}$, sehingga $\Delta_{j+1}=\left\{-\lambda_{2 t}-\sum_{k=2}^{j+1} S_{k}, \lambda_{j+1}, *, \cdots, *\right\} \in S_{2 j+2}$ dengan $*, \cdots, *$ adalah $\lambda_{j}, \lambda_{j-1}, \cdots, \lambda_{2}, \lambda_{2 t-j}, \lambda_{2 t-j+1}, \cdots, \lambda_{2 t}$.

Dalam langkah terakhir yaitu langkah $(t-1)$ gabungkan himpunan $\Delta_{t-1}=$ $\left\{-\lambda_{2 t}-\sum_{k=2}^{t-1} S_{k}, \lambda_{t-1}, *, \cdots, *\right\} \in S_{2 t-2}$ dan $\Gamma_{t}=\left\{-\lambda_{t+1}, \lambda_{t+1}\right\}$. Ambil $\varepsilon_{t}=$ $-S_{t}=-\left(\lambda_{t}+\lambda_{t+1}\right)$ Menurut Lemma 2.5 diperoleh,

$$
\begin{aligned}
\Delta_{t} & =\left\{-\lambda_{2 t}-\sum_{k=2}^{t} S_{k}, \lambda_{t}, *, \cdots, *\right\} \\
& =\left\{\lambda_{1}, \lambda_{2}, \cdots, \lambda_{t}, \lambda_{t+1}, \cdots, \lambda_{2 t-1}, \lambda_{2 t}\right\} \in S_{2 t}
\end{aligned}
$$


Selanjutnya, jika $n$ ganjil dengan $\lambda_{\frac{2 t+1}{2}}<0$ maka gabungkan $\Delta_{t}$ dengan $\Gamma_{\frac{2 t+1}{2}}=\{0\}$ didapatkan

$$
\begin{aligned}
& \Delta_{t}^{\prime}=\left\{-\lambda_{2 t}-\sum_{k=2}^{t-1} S_{k}-S_{\frac{2 t+1}{2}}, \lambda_{\frac{2 t+1}{2}}, \lambda_{t}, *, \cdots, *\right\} \in S_{2 t+1} \\
& \Delta_{t}^{\prime}=\left\{\lambda_{1}, \lambda_{2}, \cdots, \lambda_{t}, \lambda_{\frac{2 t+1}{2}}, \lambda_{t+1}, \cdots, \lambda_{2 t-1}, \lambda_{2 t}\right\} \in S_{2 t+1}
\end{aligned}
$$

Jadi, jika $A$ merupakan matriks nonnegatif simetri yang merealisasi $\Delta_{t}=$ $\bigcup_{k=1}^{t} \Lambda_{k}$ untuk $n$ genap, dan $\Delta_{t}^{\prime}=\bigcup_{k=1}^{t} \Lambda_{k} \Lambda_{\underline{n+1}}$ untuk $n$ ganjil maka $A \oplus B$ merupakan realisasi dari $\Lambda=\left\{\lambda_{1}, \lambda_{2}, \cdots, \lambda_{n}\right\} \in \stackrel{2}{2}_{n}$.

\section{Konstruksi Matriks Nonnegatif Simetri}

Untuk konstruksi matriks nonnegatif simetri dilakukan langkah-langkah sebagai berikut:

1. Misalkan $\Lambda=\left\{\lambda_{1}, \lambda_{2}, \cdots, \lambda_{n}\right\} \in S_{n}$ merupakan himpunan bilangan real sedemikan sehingga $\lambda_{1} \geq \lambda_{2} \geq \cdots \geq \lambda_{p} \geq 0>\lambda_{p+1} \geq \cdots \geq \lambda_{n}$ dengan $\lambda_{1}=-\lambda_{n}-\sum_{S_{k}<0} S_{k}$

2. Selanjutnya, bentuk partisi berikut, $\Lambda=\bigcup_{k=1}^{\left[\frac{n}{2}\right]} \Lambda_{k}$, untuk $n$ genap, atau $\Lambda=$ $\bigcup_{k=1}^{\left[\frac{n}{2}\right]} \Lambda_{k} \cup \Lambda_{\frac{n+1}{2}}$ untuk $n$ ganjil. Dengan $\Lambda_{k}=\left\{\lambda_{k}, \lambda_{n-k+1} ; k=1,2, \cdots,\left[\frac{n}{2}\right]\right.$ dan $\Lambda_{\frac{n+1}{2}}=\left\{\overline{\{}_{\frac{n+1}{2}}\right\}$ untuk $n$ ganjil.

3. Untuk $k=2,3, \cdots,\left[\frac{n}{2}\right]$ diambil $A=\left\{\Lambda_{k}: S_{k}=\lambda_{k}+\lambda_{n-k+1}<0, k=\right.$ $2,3, \cdots, t\}, B=\left\{\Lambda_{k}: S_{k}=\lambda_{k}+\lambda_{n-k+1} \geq 0, k=t+1, t+2, \cdots,\left[\frac{n}{2}\right]\right\}$. Dan $P=\left\{\Lambda_{1}=\left\{\lambda_{1}, \lambda_{n}\right\}\right\}$. Dengan $A$ atau $B$ dapat merupakan himpunan kosong untuk $n \geq 3$.

4. Setiap himpunan $\Lambda_{k} \in B$ dapat direalisasikan oleh matriks nonnegatif simetri $B_{k}$. Maka jumlah langsungnya adalah

i. untuk $n$ genap, $B=\bigoplus_{k=t+1}^{\left[\frac{n}{2}\right]} B_{k}$ adalah matriks nonnegatif simetri yang merealisasi $\Lambda=\bigcup_{k=t+1}^{\left[\frac{n}{2}\right]} \Lambda_{k}$ atau

ii. untuk $n$ ganjil, $B=\bigoplus_{k=t+1}^{\left[\frac{n}{2}\right]} B_{k} \bigoplus B_{\frac{n+1}{2}}$, dengan $B_{\frac{n+1}{2}}=\left(\lambda_{\frac{n+1}{2}}\right)$, jika $\lambda_{\frac{n+1}{2}} \geq 0$, adalah matriks nonnegatif simetri yang merealisasi $\Lambda=$ $\bigcup_{k=t+1}^{\left[\frac{n}{2}\right]} \Lambda_{k} \cup \Lambda_{\frac{n+1}{2}}$. 
5. Berikut tinjau himpunan yang tak dapat direalisasikan $\Lambda_{k} \in A$ dengan urutannya adalah $\Lambda_{2}, \Lambda_{3}, \cdots, \Lambda_{t}, t \leq\left[\frac{n}{2}\right]$ dengan $\Lambda_{\frac{2 t+1}{2}}=\left\{\lambda_{\frac{2 t+1}{2}}\right\}$, jika $\lambda_{\frac{2 t+1}{2}}<0$, untuk $n$ ganjil, gabungkan dengan $\Lambda_{1} \in P$. Untuk setiap $\Lambda_{k} \in A$ didefinisikan himpunan yang bersesuaian $\Gamma_{k}=\left\{-\lambda_{2 t-k+1}, \lambda_{2 t-k+1}\right\}$ untuk $k=2,3, \cdots, t$, adalah himpunan yang dapat direalisasikan oleh matriks nonnegatif simetri $A_{k}$, yaitu

$$
A_{k}=\left(\begin{array}{cc}
0 & -\lambda_{2 t-k+1} \\
-\lambda_{2 t-k+1} & 0
\end{array}\right)
$$

dan $\Gamma_{1}=\left\{-\lambda_{2 t}, \lambda_{2 t}\right\}$ merupakan himpunan yang dapat direalisasikan oleh matriks nonnegatif simetri $A_{1}$, yaitu,

$$
A 1=\left(\begin{array}{cc}
0 & -\lambda_{2 t} \\
-\lambda_{2 t} & 0
\end{array}\right)
$$

6. Selanjutnya gabungkan $\Gamma_{1}$ dan $\Gamma_{2}$ untuk mendapatkan $\Delta_{2}=$ $\left\{-\lambda_{2 t},-S_{2}, \lambda_{2}, \lambda_{2 t-1}, \lambda_{2 t}\right\} \in S_{4}$, maka matriks nonnegatif simetri yang merealisasi $\Delta_{2}$ adalah $M_{4}=\left(\begin{array}{cc}A_{1} & \rho_{2} v_{2} u_{2}^{T} \\ \rho_{2} v_{2} u_{2}^{T} & A_{2}\end{array}\right)$ dengan $v_{2}^{T}=u_{2}^{T}=\left(\frac{1}{\sqrt{2}}, \frac{1}{\sqrt{2}}\right)$ dan $\rho_{2}=\sqrt{\left(\lambda_{2}+\lambda_{2 t}\right)\left(\lambda_{2}+\lambda_{2 t-1}\right)} . \quad$ Kemudian gabungkan Delta $_{2}$ dengan $\Gamma_{3}$ untuk mendapatkan: $\Delta_{3}=$ $\left\{-\lambda_{2 t}-S_{2}-S_{3}, \lambda_{2}, \lambda_{3}, \lambda_{2 t-2}, \lambda_{2 t-1}, \lambda_{2 t}\right\}$ dan menurut Lemma 2.4, $\Delta_{3}$ direalisasikan oleh matriks nonnegatif simetri $M_{6}=\left(\begin{array}{cc}M_{4} & \rho_{3} v_{3} u_{3}^{T} \\ \rho_{3} v_{3} u_{3}^{T} & A_{3}\end{array}\right)$, dengan $M_{4} v_{3}=\left(-\lambda_{2 t}-S_{2}\right) v_{3},\left\|v_{3}\right\|=1$ dan $A_{4} u_{3}=\left(-\lambda_{2 t-2}\right) u_{3},\left\|v_{u}\right\|=1$ dan $\rho_{3}$ harus sedemikian sehingga $C_{3}=\left(\begin{array}{cc}\lambda_{2 t}-S_{2} & \rho_{3} \\ \rho_{3} & \lambda_{2 t}\end{array}\right)$ mempunyai nilai eigen $\lambda_{2 t}-S_{2}-S_{3}$ dan $\lambda_{3}$.

Tahap selanjutnya ditunjukkan bahwa, dalam langkah ke $(k-1)$, dapat dihitung matriks $M_{2 k}=\left(\begin{array}{cc}M_{2 k-2} & \rho_{k} v_{k} u_{k}^{T} \\ \rho_{k} v_{k} u_{k}^{T} & A_{k}\end{array}\right), k=2,3, \cdots, t$, dengan $M_{2 k-2}$ merupakan matriks nonnegatif simetri dengan spektrum $\Delta_{k-1}$, vektor $v_{k}$ dan $u_{k}$ berturut-turut adalah vektor eigen satuan dari $M_{2 k-2}$ dan $A_{k}$, masing-masing berkaitan dengan nilai eigen dengan $-\lambda_{2 t}-\sum_{j=2}^{k-1} S_{j}$ dan $\lambda_{2 t-k+1}$ dan $\rho_{k}$ harus sedemikian sehingga bahwa matriks $C_{k}=\left(\begin{array}{cc}-\lambda_{2 t}-\sum_{j=2}^{k-1} S_{j} & \rho_{k} \\ \rho_{k} & \lambda_{2 t-k+1}\end{array}\right)$ mempunyai nilai eigen $-\lambda_{2 t}-\sum_{j=2}^{k-1} S_{j}$ dan $\lambda_{k}$.

Akibat 4.1 Jika $\Lambda=\left\{\lambda_{1}, \lambda_{2}, \cdots, \lambda_{n}\right\}$ direalisasikan oleh matriks nonnegatif simetri $A$, maka $\Lambda^{\prime}=\left\{-\lambda_{1},-\lambda_{2}, \cdots,-\lambda_{n}\right\}$ direalisasikan oleh matriks $-A$. 


\section{Contoh}

Berikut ini akan diberikan satu contoh dalam menentukan matriks realisasi. Tentukan Matriks Nonnegatif Simetris (MNS) dengan spektrum $\Lambda=$ $\{7,5,1,-3,-4,-5\}$.

\section{Penyelesaian:}

$\Lambda=\{7,5,1,-3,-4,-5\}$ memenuhi kriteria realisasi dari Teorema 3.1.

Partisi $\Lambda=\Lambda_{1} \cup \Lambda_{2} \cup \Lambda_{3}$ dengan $\Lambda_{1}=\{7,-5\}, \Lambda_{2}=\{5,-4\}, \Lambda_{3}=\{1,-3\}$ dengan $S_{2}=\lambda_{2}+\lambda_{5}=1, S_{3}=\lambda_{3}+\lambda_{4}=-2$. Susun kembali $\Lambda_{1}=\{7,-5\}$, $\Lambda_{3}=\{1,-3\}$ sebagai berikut: $7>1>-3>-5$.

Kemudian definisikan $\Gamma_{1}=\{5,-5\}, \Gamma_{2}=\{3,-3\}$ yang masing-masing dapat direalisasi oleh matriks-matriks:

$$
A_{1}=\left(\begin{array}{cc}
0 & 5 \\
5 & 0
\end{array}\right), \quad A 2=\left(\begin{array}{cc}
0 & 3 \\
3 & 0
\end{array}\right)
$$

Selanjutnya gabung $\Gamma_{1}=\{5,-5\}, \Gamma_{2}=\{3,-3\}$ untuk mendapatkan $\Delta_{2}$ dengan mengambil $\varepsilon_{2}=-S_{2}=2$. Maka $\Delta_{2}=\{7,1,-3,-5\}$ yang dapat direalisasikan oleh matriks nonnegatif simetri

$$
M_{4}=\left(\begin{array}{cc}
A_{1} & \rho_{2} v_{2} u_{2}^{T} \\
\rho_{2} v_{2} u_{2}^{T} & A_{2}
\end{array}\right)=\left(\begin{array}{cccc}
0 & 5 & \sqrt{2} & \sqrt{2} \\
5 & 0 & \sqrt{2} & \sqrt{2} \\
\sqrt{2} & \sqrt{2} & 0 & 3 \\
\sqrt{2} & \sqrt{2} & 3 & 0
\end{array}\right)
$$

dengan $\rho_{2}=\sqrt{\left(5-\gamma_{i}\right)\left(3-\gamma_{i}\right)}=2 \sqrt{2}$ untuk $\gamma_{i}=7,1 ; v_{2}=\left(\frac{1}{2} \sqrt{2}, \frac{1}{2} \sqrt{2}\right)$, $u_{2}=\left(\frac{1}{2} \sqrt{2}, \frac{1}{2} \sqrt{2}\right)$, Sedangkan matriks yang merealisasi $\Delta_{2}=\{5,-4\}$ adalah $A_{3}=\left(\begin{array}{cc}\frac{1}{2} & \frac{9}{2} \\ \frac{1}{2} & \frac{9}{2}\end{array}\right)$. Maka matriks nonnegatif simetri yang merealisasi $\Lambda=$ $\{7,5,1,-3,-4,-5\}$ adalah

$$
M_{6}=\left(\begin{array}{cccccc}
0 & 5 & \sqrt{2} & \sqrt{2} & 0 & 0 \\
5 & 0 & \sqrt{2} & \sqrt{2} & 0 & 0 \\
\sqrt{2} & \sqrt{2} & 0 & 3 & 0 & 0 \\
\sqrt{2} & \sqrt{2} & 3 & 0 & 0 & 0 \\
0 & 0 & 0 & 0 & \frac{1}{2} & \frac{9}{2} \\
0 & 0 & 0 & 0 & \frac{1}{2} & \frac{9}{2}
\end{array}\right)
$$

Sedangkan untuk menentukan matriks yang merealisasikan $\Lambda^{\prime}=$ $\{-7,-5,-1,3,4,5\}$ dapat digunakan Akibat 4.1, yaitu diperoleh matriks $-M_{6}$. 


\section{Kesimpulan}

Beberapa hal yang dapat disampaikan dalam kesimpulan ini adalah:

a. Misalkan $\Lambda=\left\{\lambda_{1}, \lambda_{2}, \cdots, \lambda_{n}\right\}$ merupakan sebuah himpunan bilangan real sedemikian sehingga $\lambda_{1} \geq \lambda_{2} \cdots \geq \lambda_{p} \geq 0>\lambda_{p+1} \geq \cdots \geq \lambda_{n}$. Supaya konstruksi matriks nonnegatif simetri dapat dilakukan, maka haruslah $\Lambda$ memenuhi kriteria realisasi.

b. Untuk konstruksi matriks nonnegatif simetri dapat dilakukan dengan menggunakan jumlah langsung $B=\bigoplus B_{k}$ atau dan jumlah matriks $\mathrm{C}$.

c. Jika $\Lambda=\left\{\lambda_{1}, \lambda_{2}, \cdots, \lambda_{n}\right\}$ dapat direalisasikan oleh matriks nonnegatif simetri $A$, maka $\Lambda^{\prime}=\left\{-\lambda_{1},-\lambda_{2}, \cdots,-\lambda_{n}\right\}$ dapat direalisasikan oleh matriks $-A$.

\section{Pustaka}

[1] Anton H, and Rorres C, 1991, Elementary Linear Algebra Applications Version, Sixth Edition, John Wiley \& Sons. Inc.,New York.

[2] Fiedler.M, 1974, Eigenvalues Of Nonnegative Symmetric Matrices, Linear Algebra Appl. 9, pp. 119-142.

[3] Lancaster P., and Tismenetsky M., 1985, The Theory Of Matrices, Akademi Press, New York.

[4] Noble B.,and Daniel J.W.,1988,Applied Linear Algebra,PrenticeHall/Englewood Cliffs, New Jersey.

[5] Soto R., 2003, Existence And Construction Of Nonnegative Matrices With Real Prescribed Spectrum, Linear Algebra Appl. 369, pp.169-184

[6] Soto R., 2005, Realizability By Symmetric Nonnegative Matrices, Proyecciones, Vol.24, No 1, pp 65-78.

[7] Yacob B., 1990, Linear Algebra, W.H. Freeman And Company, New York 
